Frontiers: The Interdisciplinary Journal of Study Abroad Volume 32, Issue 2, pp. 163-174

(C) Jeffrey W. Overby

This work is licensed under the Creative Commons Attribution-NonCommercial-

NoDerivatives 4.0 International License.

DOI 10.36366/frontiers.v32i2.472

$$
\text { FORUM }
$$

ON EDUCATION

ABROAD

\title{
Alcohol Expectations of Short-
}

\section{Term, Faculty-Led Trip Leaders:}

\section{A Survey of Current Practices}

Jeffrey W. Overby ${ }^{1}$

\section{Abstract}

Although a growing body of research examines alcohol consumption among American university students during study abroad, there is little to no research on alcohol-related policies and behavior by faculty leaders during study abroad. This research reports survey results from 66 U.S. colleges and universities on the current state of formal policies for faculty-led trip leaders. The quantitative findings reveal: 1) $93.9 \%$ of responding institutions allow trip leaders to consume alcohol during short-term, faculty-led study abroad trips; and 2) even those institutions that discourage faculty consumption with students allow such consumption in certain situations, including group dinners, winery and brewery tours, religious ceremonies, and receptions. The qualitative findings reveal three themes: 1) faculty should exhibit responsible consumption; 2 ) drinking with students is discouraged but allowed in certain situations; and 3) faculty leaders are never allowed to purchase alcohol for students. The manuscript concludes with a call for additional research on several topics.

\section{Keywords:}

Study abroad, alcohol, faculty, consumption, universities

1 BeLmont UniVersity, TenNeSSEE, USA

Corresponding author: Jeffrey W. Overby, Belmont University, email:

jeff.overby@belmont.edu 


\section{Introduction}

There has been no shortage of anecdotal and empirical research in recent years regarding alcohol use during study abroad programs. However, nearly all research has examined alcohol use and alcohol policies for student participants. Research on faculty policies and faculty leader use is almost nonexistent. Given the increase in short-term faculty-led study abroad trips, this issue is likely to become more significant among U.S. colleges and universities.

\section{Study Abroad Trends}

Study abroad participation among U.S. institutions of higher education has grown significantly over the past several decades as universities, governmental and nongovernmental organizations alike tout the benefits. According to the 2019 Institute of International Education (IIE) Open Doors Report (Institute of International Education, 2019), the percentage of U.S. students receiving academic credit abroad totaled over 341,000 in 2017/18, a 2.7 percent increase over the previous academic year. Moreover, the number more than tripled over the past two decades. Overall, approximately 16 percent of students pursuing a bachelor's degree in the U.S. study abroad before graduating.

In terms of types of study abroad programs by U.S. institutions in 2017/18, 64.6 percent were short-term (summer, or eight weeks or less), 33.1 percent were mid-length (one semester, or one or two quarters, and 2.3 percent were long-term (academic or calendar year). The IIE reports that participation in short-term programs has continued to grow since 2012 whereas long-term study abroad participation has continued to decrease (Institute of International Education, 2017). The short-term growth has primarily been concentrated in two sub-categories - summer terms less than two weeks and programs during the academic year of less than two weeks (Institute of International Education, 2017). Even though IIE's Open Doors data does not specify whether short-terms programs are faculty-led, there is evidence that faculty-led programs account for growing share of total programs (Di Gregorio, 2015).

Given that short-term, faculty-led study abroad programs are becoming more popular among universities throughout the U.S. (West Martin, 2018) the likelihood of student and faculty interactions involving alcohol will continue to increase (Pedersen, Larimer, \& Lee, 2010). This is significant from a student and faculty perspective given previous research on the benefits of faculty engagement in faculty-led programs. For example, active faculty engagement has been linked to the success of faculty-led study abroad programs through a variety of ways, including increasing student participation rates (Doyle et al., 
2010; Paus \& Robinson, 2008), credit transfer (Woodruff, Gladding, Knudson, \& Stallman, 2005) and academic integration of education abroad into relevant curricula (Anderson, Hubbard, \& Lawton, 2015; Giedt, Gokcek, \& Ghosh, 2015; Niehaus, Reading, Nelson, \& Wegener, 2018), intercultural sensitivity (Anderson, Lawton, Rexeisen, \& Hubbard, 2006; Gullekson, Tucker, Coombs, \& Wright, 2011; Taylor \& Finley, 2010), and on-the-ground assistance for students (Keese \& O’Brien, 2011). Similarly, faculty gain knowledge and experiences that they can incorporate into the classroom, gain legitimacy with students, develop better relationships with students, develop new research ideas, and they may strengthen their portfolio for tenure and promotion (Ellinghaus, Spinks, Moore, Hetherington, \& Atherton, 2019; Keese \& O’Brien, 2011). The question remains as to whether there might be similar benefits and/or consequences of faculty intervention in situations where alcohol is involved during faculty-led study abroad.

\section{Alcohol Consumption and Study Abroad}

Despite the many benefits of study abroad participation, research has also highlighted some negative outcomes, including increased stress on those with mental health issues and reverse culture shock, illness, larceny, assault, accidents, and excessive alcohol consumption (Quigley, 2013; Simmons \& Pedersen, 2017; Smucker et al., 2019). Alcohol consumption has, by far, received the most attention in the literature, with research generally showing increased alcohol consumption by U.S. students when studying abroad (Epstein, 2005; Hummer, Pedersen, Mirza, \& Labrie, 2010; Pedersen et al., 2010; Poggioli, 2008). Excessive alcohol consumption ranks second only to poor judgment as a contributing factor in reported negative incidents abroad (Simmons \& Pedersen, 2017). For example, 50 percent of reportable Title IX sexual incidents abroad have been attributed to alcohol (Simmons \& Pedersen, 2017).

Initial research focused on characteristics of drinking behavior during study abroad. For example, a number of characteristics of students have been identified that place them at greater risk of alcohol abuse while abroad, including being male, white, in a fraternity or sorority, under age 21 and with a lower grade point average (Pedersen, Skidmore, \& Aresi, 2014; Pedersen et al., 2010). These studies have also identified behavioral factors that place students at greater risk than others when abroad, including drinking intentions before departure, heavier pre-abroad drinkers, testing high in sensation seeking, and having more spending money. Interestingly, even majors seem to be an indicator, with cultural studies and language majors less likely to drink heavily than other majors (Pedersen et al., 2014). Pedersen, Neighbors, Larimer, and Lee (2011) reported that heavier drinking students may self-select into study abroad programs. As noted in the previous section, one of the disadvantages of shortterm, faculty-led programs is higher alcohol consumption among students. 
Other research has focused on motivations and consequences of alcohol consumption during study abroad. For example, several researchers (Arnett, 2004; Cooper, 1994; Festinger, 1954; Pedersen et al., 2011) have shown that a significant motivating factor for students both at home and abroad is a desire to fit in with peers and that this motivation often leads to increased drinking while abroad along with increased risk for alcohol-related consequences. Researchers have also shown that study abroad students tend to misperceive the drinking behavior of peers which can lead to more significant alcohol abuse while abroad (Pedersen, LaBrie, \& Hummer, 2009; Pedersen et al., 2011). Hummer et al. (2010) reported a number of negative consequences from alcohol misuse during study abroad, including hangover, embarrassing situation, risky situations, missing class, regretful sexual situations, blacking out, passing out and even injury.

Recently, researchers have started to examine behavior change strategies in association with study abroad alcohol use. Pedersen et al. (2011) developed the Sojourner Adjustment Measure (SAM). Sojourner Adjustment was first defined as "the psychological adjustment of relatively short-term visitors to new cultures where permanent settlement is not the purpose of the sojourn" (Church, 1982). SAM is composed of four positive factors (social interaction with host nationals, cultural understanding and participation, language development and use, host culture identification) and two negative factors (social interaction with co-nationals, homesickness/feeling out of place). Pedersen et al. (2011) found that negative sojourner adjustment contributes to greater alcohol consumption risk whereas positive sojourner adjustment protects students from negative consequences. Specifically, students who engaged with their cultural environment (interacted with locals and attempted fit in) had less difficulty adapting to living abroad, used alcohol in more culturally appropriate way, and did not experience multiple negative consequences. Conversely, students who spent the majority of their time with other American students and felt out of place in the local culture were at greater risk for negative drinking consequences (Pedersen, Neighbors, Lee, \& Larimer, 2012).

In one of the first studies of intervention strategies, Pedersen, Neighbors, Atkins, Lee and Larimer (2017) recently tested an online study abroad intervention based on social norms as a method for preventing heavy alcohol use and negative consequences among study abroad students. The study involved brief online interventions intended to correct misperceptions of country-specific native adult drinking norms and promote engagement with the culture prior to departure on a study abroad trip. The results confirmed that students receiving interventions to correct social norm perceptions drank less over the course of the study abroad trip compared to control group participants. However, the results were only evident for light drinkers. Interestingly, promotion of cultural engagement only seemed to be effective when combined 
with interventions to correct social norm perceptions especially for problematic drinking students. The authors (Pedersen et al., 2017) concluded that "simply receiving encouragement and information about engaging the culture abroad is not sufficient to prevent heavy drinking and consequences” (p. 11).

\section{Research Questions}

This review of the literature demonstrates that student alcohol consumption tends to increase during study abroad programs, particularly short-term programs, and such consumption can lead to numerous problems and negative outcomes. Research has shown that interactions with co-nationals and interventions during the program can significantly reduce heavy drinking by students. But where does the faculty leader fit in? Do faculty even drink during short-term, faculty-led study abroad programs? And if yes, is there any correlation between faculty alcohol use and student use and can faculty leaders influence student alcohol consumption during such programs? In order to examine these questions, the first issue that must be addressed is the current state of formal policies adopted by universities for faculty-led trip leaders. The remainder of this manuscript is intended to address this question.

\section{Methodology}

Given the exploratory nature of the research question and the lack of extant literature on the topic, this research followed a discovery-oriented methodology. The method of data collection was primarily qualitative. During the spring and summer of 2018, the lead researcher sent identical emails to a convenience sample of directors of study abroad offices at universities throughout the U.S. The email invitation indicated that the researcher was benchmarking study abroad policies in relation to alcohol use by program directors (in addition to students) during faculty-led study abroad trips. The invitation requested email feedback regarding written policies for program leaders. The target sample included both private and public universities, religiously affiliated and non-religiously affiliated, and universities of varying sizes. To supplement the email approach, a research assistant also searched university websites for evidence of written policies for faculty-led trip leaders. Though not all respondents clearly referred to short-term, faculty-led programs, the original request specifically addressed this context and the supplemental website research also focused specifically on faculty-led policies.

Once collected, for the descriptive quantitative analysis, the researchers coded the data using guidelines consistent with content analysis. Content analysis adds methodological rigor to the coding because of the ability to quantify the qualitative data analysis (Kolbe \& Burnett, 1991; Strauss \& Corbin, 1990). Content codes included the following: 1) faculty consumption (five 
categories: a) does NOT allow faculty consumption at any time; b) allows faculty consumption ONLY when a trip provider is in charge; c) discourages faculty consumption at any time; d) allows faculty consumption when not in the presence of students; e) allows faculty consumption in presence of students; 2) type of institution (private/public); and 3) religious affiliation of institution (religion/non-religious). A sixth category was added to alcohol consumption after it became apparent that the vast majority of institutions allowed faculty alcohol consumption but provided no written policy to faculty leaders

To supplement the quantitative analysis, the author and a research assistant conducted a qualitative theme analysis of the textual responses (Carey, Wenzel, Reilly, Sheridan, \& Steinberg, 1998). This involved a process including data reduction, conclusion drawing and verification over multiple reviews of the data (Baskerville \& Pries-Heje, 2001; Miles \& Huberman, 1994). The three themes that emerged were: 1) faculty should lead by example with responsible consumption; 2) drinking with students is discouraged, but it is allowed in certain situations; and 3) faculty leaders are never allowed to purchase alcohol for students. After completing the initial coding of the data in each group, the researchers met to resolve coding differences (Yu, King, \& Yoon, 2010). Because of the relatively small number of codes, the research team was able to obtain 100 percent inter-coder agreement on the coding of the text units (Yu et al., 2010).

\section{Results}

\section{Descriptive Findings}

A total of 205 universities were contacted, and 66 replied, resulting in a response rate of $32.2 \%$. Of the responses, 39 (59.1\%) represented private universities and 27 (40.9\%) represented public universities, 20 (30.3\%) were from religiously-affiliated institutions and 46 (69.7)\% were from nonreligiously affiliated institutions. Table 1 highlights the quantitative findings.

As evident in Table 1, 93.9\% of respondent universities allow faculty alcohol consumption in some form during short-term, faculty-led study abroad trips, and only $6.1 \%$ completely forbid such. Of those that completely forbid faculty consumption, all of them are private, religiously-affiliated schools. 
Table 1. Survey Responses.

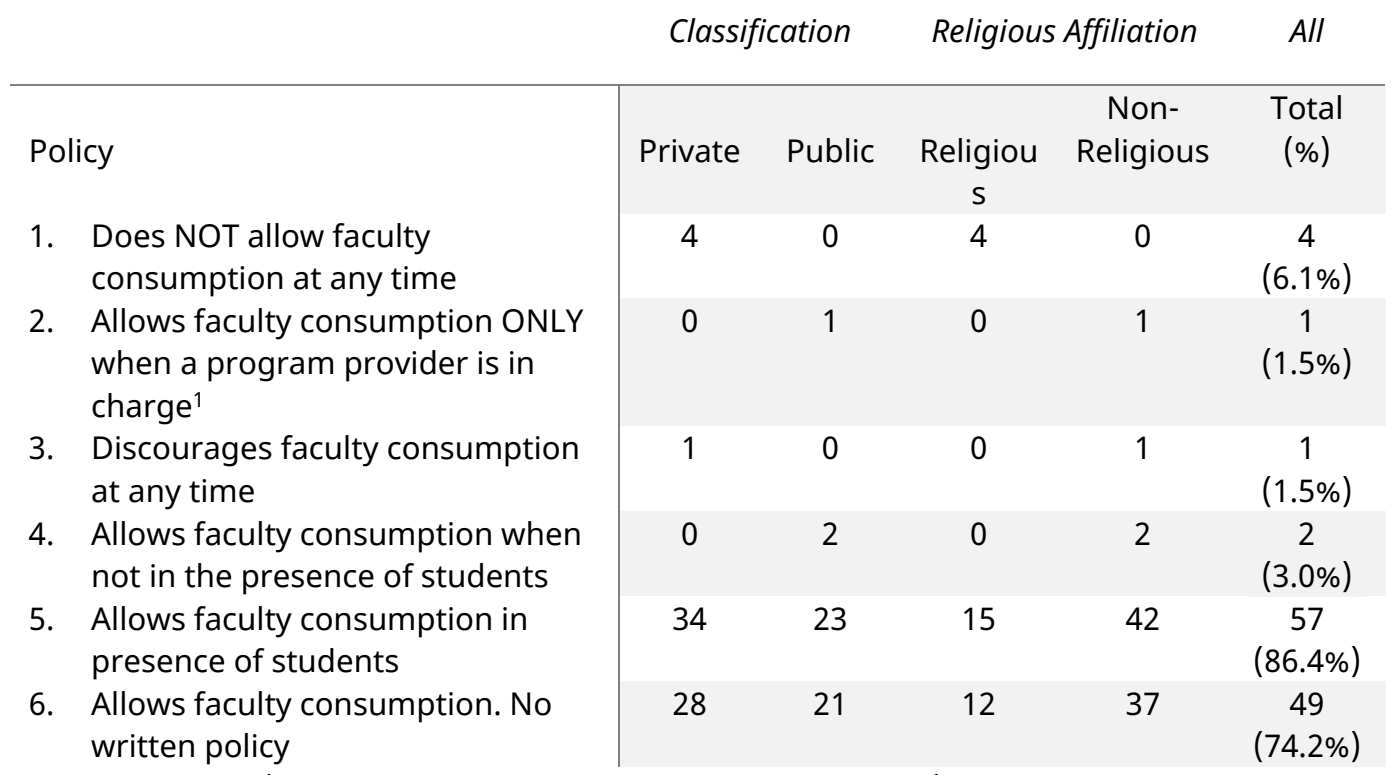

Note: Category 6 (Allows faculty consumption. No written policy) includes nine universities that were also counted in Categories 2-5.

\section{Qualitative Findings}

In order to provide depth to the qualitative findings, verbatim excerpts will be utilized when possible. Several themes emerged from the qualitative content analysis.

Theme 1: Faculty should lead by example with responsible consumption.

A number or respondents commented that faculty serve as the best model for responsible alcohol consumption. Some even provided examples of what responsible behavior involves. Sample excerpts are below:

"While there is no prohibition against faculty or staff having a beer or a glass of wine with a student of legal age while abroad, the College expects program leaders to demonstrate a standard of responsible drinking

\footnotetext{
${ }^{1}$ According to The Forum on Education Abroad's Glossary (n.d.) definition, a program provider is "an institution or organization that offers education abroad program services to students from a variety of institutions. A program provider may be a college or university, a nonprofit organization, a for-profit business, or a consortium.” These organizations have prepackaged programs and arrangements with universities overseas. They often have an on-site coordinator who helps students with housing, travel, medical care and more. Many providers issue a transcript with a U.S. college or university as the school of record allowing for easier credit transfer to the student's home institution. Students usually pay the provider directly instead of their home institution.
} 
around students. It should go without saying that leaders should avoid playing drinking games, buying drinks for students, etc.”

"If students are individually purchasing alcohol at a group function in the presence of the University Representative, it is the responsibility of the University Representative to monitor responsible alcohol consumption and discourage excessive consumption of alcohol.

"It is also important for [program leaders] to limit to consumption of alcohol in the presence of students, both in order to model responsible and culturally appropriate behavior, but also to manage perceptions and risks that may arise from social interactions between program faculty, staff, and students when alcohol is present."

"Faculty members are expected to lead by example.”

\section{Theme 2: Drinking with students is discouraged, but it is allowed} in certain situations.

A number of universities, though they discourage consumption in the presence of students, allow such consumption during specific situations, such as: 1) group meals or program receptions, 2) visits to breweries and wineries, 3) sitting around a table discussing the events of the day, 4) at a Seder dinner, and 5) in countries where it would be customary to drink wine or beer with a meal.

"We ask that faculty leaders do not consume alcohol with the students. They are also asked to limit the purchase of alcohol for their group as much as possible. Obviously, visiting a winery may constitute an exception, or sometimes a partner institution or business will offer a banquet where wine is provided, and therefore it would be culturally awkward to enforce a non-alcohol policy.”

"Faculty are also told they should not drink with students, but if they have a beer or wine with dinner and students are present, we have not seen this as a big deal."

"We advise leaders to be conscious about drinking with students because of the unnecessary complications that can arise if there are rumors about faculty/staff who are "going out drinking" with students...So practically speaking, we suggest the appropriateness of having a drink in the context of a dinner or even perhaps one drink at a student party but making boundaries very clear. Included with that is the advice that professors not initiate "a drink" and/or "drinking” with students even on personal time and personal resources.” 
Theme 3: Faculty leaders are never allowed to purchase alcohol for students.

This theme was consistent across all types of universities and study abroad programs represented in the sample. The one exception that was cited by multiple respondents was when alcohol was included in the overall program fee by study abroad providers or on restaurant set menus.

"[University] strongly discourages faculty from providing alcohol for or purchasing alcohol for the students participating in study abroad programs; faculty are not permitted to purchase alcohol from program funds.”

"Faculty may not purchase alcohol for students at any time."

"Of course, university funds are not to be used for alcohol except in cases where the whole group benefits (legally to the laws of the land) and more because of special occasions, such as a closing banquet or the like.”

\section{Discussion and Conclusions}

This research indicates that the vast majority of responding U.S. institutions of higher learning allow trip leaders to consume alcohol during short-term, faculty-led study abroad trips. The circumstances of that usage vary somewhat, as many universities allow responsible faculty consumption in the presence of students though many others discourage consumption in such circumstances. Even those institutions that discourage faculty consumption with students allow such consumption in certain situations, including group dinners, winery and brewery tours, religious ceremonies, and receptions. The handful of institutions that completely forbid trip leader consumption during study abroad are all religious institutions that appear to have philosophical prohibitions against alcohol use.

This research certainly is subject to some shortcomings. One shortcoming is that it only examined institutional consumption policies rather than actual behavior of faculty leaders in short-term, faculty-led programs. Additional research is needed to determine the current state of such behavior and whether it is a significant problem. A second shortcoming is that this research examined policies of only U.S. institutions. It is expected that the policies of non-U.S. institutions will be significantly more permissive, but to date, there is only anecdotal evidence.

Aside from the future research issues discussed above, a final research question is whether/how faculty consumption in the presence of students can positively model responsible behavior for students. Intuitively, one can argue 
that seeing responsible alcohol consumption by trip leaders would positively influence responsible alcohol consumption among students. However, there is not enough evidence to date to answer this question.

\section{Acknowledgement}

The author would like to thank an anonymous research assistant for their help with data collection and coding.

\section{Author Biography}

Dr. Jeffrey W. Overby serves as Professor and Director of the Center for International Business at Belmont University. His responsibilities include teaching marketing and international business, establishing study abroad relationships with foreign universities, and promoting internationalization within the Jack C. Massey College of Business and the greater Nashville community. He also regularly leads study abroad programs, including programs in Argentina, Austria, Botswana, Chile, China, Czech Republic, France, The Netherlands, Poland, South Africa, South Korea, Spain, and United Arab Emirates.

\section{References}

Anderson, P. H., Hubbard, A., \& Lawton, L. (2015). Student Motivation to Study Abroad and Their Intercultural Development. Frontiers: The Interdisciplinary Journal of Study Abroad, XXVI(Fall), 39-52.

Anderson, P. H., Lawton, L., Rexeisen, R. J., \& Hubbard, A. C. (2006). Short-term study abroad and intercultural sensitivity: A pilot study. International Journal of Intercultural Relations, 30(4), 457-469. doi:10.1016/j.ijintrel.2005.10.004

Arnett, J. J. (2004). Emerging adulthood: The winding road from the late teens through the twenties. New York: Oxford University Press.

Baskerville, R., \& Pries-Heje, J. (2001). A multiple-theory analysis of a diffusion of information technology case. Information Systems Journal, 11(3), 181-212. doi:https://doi.org/10.1111/j.1365-2575.2001.00106.x

Carey, J. W., Wenzel, P. H., Reilly, C., Sheridan, J., \& Steinberg, J. M. (1998). CDC EZ-Text: Software for management and analysis of semi-structured qualitative data sets. Cultural Anthropology Methods, 10(1), 14-20. doi:https://doi.org/10.1177/1525822X980100010501

Church, A. (1982). Sojourner Adjustment. Psychological Bulletin, 91(3), 540-572. doi:http://dx.doi.org/10.1037/0033-2909.91.3.540

Cooper, M. L. (1994). Motivations for alcohol use among adolescents: Development and validation of a four-factor model. Psychological Assessment, 6(2), 117-128. doi:http://dx.doi.org/10.1037/1040-3590.6.2.117

Di Gregorio, D. (2015). Fostering experiential learning in faculty-led study-abroad programmes. In V. Taras \& M. A. Gonzalez-Perez (Eds.), The Palgrave handbook of 
experiential learning in international business (pp. 569-584). London: Palgrave Macmillan.

Doyle, S., Gendall, P., Meyer, L. H., Hoek, J., Tait, C., McKenzie, L., \& Loorparg, A. (2010). An investigation of factors associated with student participation in study abroad. Journal of Studies in International Education, 14(5), 471-490. doi:https://doi.org/10.1177/1028315309336032

Ellinghaus, K., Spinks, J., Moore, G., Hetherington, P., \& Atherton, C. (2019). Study Tour Improved Their Classroom Teaching. Frontiers: The Interdisciplinary Journal of Study Abroad, XXXI(1), 169-189.

Epstein, J. (2005). Last call for U.S. students studying abroad? Continuing concerns about alcohol use and abuse during study abroad. SAFETI Online Newsletter, 3(1). Retrieved from http://globaled.us/safeti/v3n12005ed last call for us students.asp

Festinger, L. (1954). A theory of social comparison processes. Human Relations, 7(2), 117-140. doi:https://doi.org/10.1177/001872675400700202

Forum on Education Abroad, The. (n.d.). Glossary. Retrieved from https://forumea.org/resources/glossary/

Giedt, T., Gokcek, G., \& Ghosh, J. (2015). International education in the 21st century: The importance of faculty in developing study abroad research opportunities. Frontiers: The Interdisciplinary Journal of Study Abroad, 26(Fall), 167-186.

Gullekson, N. L., Tucker, M. L., Coombs, G. J., \& Wright, S. B. (2011). Examining intercultural growth for business students in short-term study abroad programs: Too good to be true? Journal of Teaching in International Business, 22(2), 91-106. doi:https://doi.org/10.1080/08975930.2011.615672

Hummer, J. F., Pedersen, E. R., Mirza, T., \& Labrie, J. W. (2010). Factors associated with general and sexual alcohol-related consequences: An examination of college students studying abroad. Journal of Student Affairs Research and Practice, 47(4), 421-438. doi:10.2202/1949-6605.6134

Institute of International Education. (2017). Open doors report on international educational exchange. Retrieved from http://www.iie.org/Research-and-Publlications/OpenDoors\#.WDupyJMrLaY

Institute of International Education. (2019). Open doors report on international educational exchange. Retrieved from https://www.iie.org/Research-and-Insights/Open-Doors/

Keese, J. R., \& O’Brien, J. (2011). Learn by going: Critical issues for faculty-led study-abroad programs. The California Geographer, 51, 3-24.

Kolbe, R. H., \& Burnett, M. S. (1991). Content-analysis research: An examination of applications with directives for improving research reliability and objectivity. Journal of Consumer Research, 18(2), 243-250. doi:http://dx.doi.org/10.1086/209256

Miles, M. B., \& Huberman, A. M. (1994). Qualitative data analysis (2nd ed.). Newbury Park, CA: Sage.

Niehaus, E., Reading, J., Nelson, M. J., \& Wegener, A. (2018). Faculty Engagement in Cultural Mentoring as Instructors of Short-Term Study Abroad Courses. Frontiers: The Interdisciplinary Journal Of Study Abroad, XXX(2), 77-91.

Paus, E., \& Robinson, M. (2008). Increasing study abroad participation: The faculty makes the difference. Frontiers: The Interdisciplinary Journal of Study Abroad, 17(Fall), 3349.

Pedersen, E. R., LaBrie, J. W., \& Hummer, J. F. (2009). Perceived behavioral alcohol norms predict drinking for college students while studying abroad. Journal of Studies on Alcohol and Drugs, 70(6), 924-928. doi:http://dx.doi.org/10.15288/jsad.2009.70.924 
Pedersen, E. R., Neighbors, C., Atkins, D. C., Lee, C. M., \& Larimer, M. E. (2017). Brief online interventions targeting risk and protective factors for increased and problematic alcohol use among American college students studying abroad. Psychology of Addictive Behaviors, 31(2), 220-230. doi:10.1037/adb0000242

Pedersen, E. R., Neighbors, C., Larimer, M. E., \& Lee, C. M. (2011). Measuring Sojourner Adjustment among American students studying abroad. International Journal of Intercultural Relations, 35(6), 881-889. doi:10.1016/j.ijintrel.2011.06.003

Pedersen, E. R., Neighbors, C., Lee, C. M., \& Larimer, M. E. (2012). Not all those who wander are lost: Examining the impact of Sojourner Adjustment and drinking motives on alcohol consequences experienced by Americans studying in foreign countries. Journal of Studies on Alcohol and Drugs, 73(6), 1005-1015.

Pedersen, E. R., Skidmore, J. R., \& Aresi, G. (2014). Demographic and predeparture factors associated with drinking and alcohol-related consequences for college students completing study abroad experiences. Journal of American College Health, 62(4), 244-254. doi:10.1080/07448481.2014.887573

Pedersen, E. R., Larimer, M. E., \& Lee, C. M. (2010). When in Rome: Factors associated with changes in drinking behavior among American college students studying abroad. Psychology of Addictive Behaviors, 24(3), 535-540. doi:10.1037/a0019863

Poggioli, S. (2008). Study abroad students gone wild in Italy?: National Public Radio.

Quigley, R. L. (2013). The dark side to studying abroad - And how to address it. The Huffington Post. Retrieved from http://www.huffingtonpost.com/robert-quigley-mddphil/mental-health-study-abroad b 2852843.html

Simmons, D., \& Pedersen, E. R. (2017). Alcohol: Research driven responses to moderate behavior. Paper presented at the 8th Annual Standards of Good Practice Institute: Beyond the Basics of Health, Safety, Security and Risk Management.

Smucker, S., Pedersen, E. R., Labrie, J. W., D’Amico, E. J., Farris, C., Klein, D. J., \& Griffin, B. A. (2019). There and Back Again. . Safely: Examining Students’ Reports of Substance Use and Sexual Assault Prevention Program Receipt Prior to Departure Abroad. Frontiers: The Interdisciplinary Journal of Study Abroad, XXXI(2), 51-62.

Strauss, A., \& Corbin, J. (1990). Basics of qualitative research: Grounded theory procedures and techniques. Newbury Park, CA: Sage Publications.

Taylor, S. L., \& Finley, J. B. (2010). An examination of U.S. AACSB International AccountingAccredited schools to determine global travel experience requirements in accounting masters programs. Journal of Education for Business, 85(2), 119-123. doi:https://doi.org/10.1080/08832320903259616

West Martin, A. (2018). Creating community: Mitigating risk during short-term faculty-led programs abroad. Prescott College,

Woodruff, G., Gladding, S., Knudson, M., \& Stallman, E. (2005). The Forum on Education Abroad: A baseline survey of curriculum integration in education abroad. In Survey. Northampton, MA: The Forum on Education Abroad.

Yu, J. H., King, K. W., \& Yoon, H. J. (2010). How much are health websites influenced by culture? Content analysis of online diet programs in the United States, the United Kingdom, and Korea. Journal of Promotion Management, 16(3), 331-359. doi:https://doi.org/10.1080/10496490903294703 